\title{
Research Paper: Prevalence Rate of Postural Damages, Disorders \& Anomalies among Computer Users
}

\author{
Arvin Fathi ${ }^{1 *}$
}

1. Department of Computer-Software Engineering, Faculty of Engineering, Ferdowsi University of Mashhad, Mashhad, Iran.

Citation: Fathi A. Prevalence Rate of Postural Damages, Disorders and Anomalies Among Computer Users. Physical Treatments. 2016; 6(1):59-65. https://doi.org/10.18869/NRIP.PTJ.6.1.59

: https://doi.org/10.18869/NRIP.PTJ.6.1.59

Article info:

Received: 17 Nov. 2015

Accepted: 03 Mar. 2016
Keywords:

Damage, Musculoskeletal, Computer users

\begin{abstract}
A B S T RA C T
Purpose: Globalization of computer use in the past two decades has increased the prevalence of musculoskeletal problems and different damages to computer users. Therefore, the present study aims to determine the prevalence rate of musculoskeletal damages and postural anomalies and disorders among computer users.
\end{abstract}

Methods: This is a descriptive research study carried out as a field project on 160 university students with 3 years of experience working with computers. The data were collected using a questionnaire developed by the researcher, which was of high reliability and validity. Moreover, for evaluation of the changes in postural alignment, the New York posture rating chart was used. Data analyses were performed by using descriptive statistics, which was done using Excel software and SPSS version 21.0.

Results: The findings of this study revealed that the participants suffered from pain in the head $(81.25 \%)$, eyes $(87.50 \%)$, neck $(100 \%)$, shoulders $(100 \%)$, waist $(81.25 \%)$, wrist $(100 \%)$, fingers $(100 \%)$, pelvis $(93.75 \%)$, and knees $(100 \%)$. Risk factors such as not using suitable chairs, incorrect way of sitting, and lack of movement (i.e. inactivity during work) were of great significance. Moreover, the findings of this research indicated the following as the prevalent postural anomalies among university students: $85 \%$ forward head posture, $90 \%$ drooping shoulders, $70 \%$ pectoral kyphosis, $65 \%$ posterior pelvic tilt, $40 \%$ bowed knees or $\mathrm{X}$-shaped legs, and $30 \%$ ankle rotation.

Conclusion: Sore neck and shoulders, sore eyes, painful wrist, and fingers are very common among computer users. Forward head posture, drooping shoulder (that of the user's dominant hand), and bowed knees or X-shaped legs were found to be the basic and prevalent postural problems among university students. Inactivity caused by over-work and not attending to ergonomic principles while working was among the key risk factors observed in this study.

\footnotetext{
* Corresponding Author:

Arvin Fathi, MSc.

Address: Department of Computer-Software Engineering, Faculty of Engineering, Ferdowsi University of Mashhad, Mashhad, Iran. Phone: +98 (915) 1171993

E-mail: arvin.fathi@ymail.com
} 


\section{Introduction}

1

dvancements in science and technology, as well as the efforts to speed up common activities and official affairs worldwide, have necessitated the use of modern equipment. This rising trend has been achieved due to human novelties and innovations. The dominant belief is that consumption of less time and energy with the help of advanced science paves the way for more satisfaction. However, each invention comes along with certain disadvantages, such as unemployment or damages caused by the use of new technology [1-2].

Computer is one such instrument that was initially used in a restricted way but has now become a commercial good for export in small and big countries. Its applications also include significant governmental and official systems, universities, and minor companies [3-4]. However, computer manufacturing companies and all other related organizations have paid less attention to the common standards used in the world. For a higher sale and income, manufacturers believe in designing various computers of attractive models and forms so as to attract more customers in the market [1].

Organizations using this instrument pay no heed to the workstation, type of room and lightings used, one's positioning in front of the computer system, and so on. They demand more efforts from users, and a lack of attention to these standards would cause severe damages to the users $[1,3]$. Musculoskeletal damages caused by frequent computer use comprise a major group of harmful diseases that can lead to fatigue, pain, and disability in users' limbs. In these diseases, the tendons, ligaments, joints, nerves, blood muscles, and veins are damaged [3]. A myriad of research has showed that these diseases have a wide range of economic effects on users, organizations, and societies [5]. In many countries, preventing diseases among computer users is a national priority [6].

Body positioning, as viewed by the Posture Committee in the Academy of Orthopedic Surgeons, is a relative alignment of the different parts of the body. A proper body posture is defined as a balanced muscular and skeletal state accompanied by the proper alignment of different body segments. Maintaining body in that position should require the least amount of energy. The privilege of a desirable body posture is that it poses the least stress possible on body tissues $[1,2]$. Anomaly or defective body posture is any modification in the relative alignment of body parts accompanied by an excessive pressure or tension on body tissues and structures $[1,3]$.
This postural anomaly caused by contextual stimuli is often of a correctable or reversible type [4]. On the one hand, it is caused by the mechanical life, minimal use of one's body and inactivity, and on the other hand, it is a function of excessive attention of modern human to an easier and apparently more pleasant life [5]. In fact, people often spend hours in a stable and inappropriate position working or using a computer [6]. According to the reports, people's working hours from 1997 to 2003 have changed from 5.9 to an average 14.6 hours per day. However, this rising trend has certain side effects such as muscular disorders, headache, and sore neck $[7,8]$.

A body of research has indicated a correlation between using computer and these pains. The results of a study on computer users in New Zealand showed that sore limbs is the most common musculoskeletal side effect in $81 \%$ of the subjects [9]. The prevalence and risk factors of these diseases in developing countries are being investigated [7]. The relevant risk factors are yet not completely known [9]. Previous studies have also revealed that sore neck and shoulder are significantly correlated with lower health state and quality of life [10]. The Bureau of Statistics in the U.S. stated in 1996 that $64 \%$ of all disability cases as a function of computer use pertain to sore neck and shoulders [11]. Pain in computer users' body limbs in the U.S. has imposed medical costs as high as 45 to 55 billion dollars [7].

Advanced science and technology and efforts to speed up official and daily activities have made computer use an indispensable part of social life. As an instance, in 2006, the number of PCs in the U.S., a developed country, was estimated to be about 240 million sets, and in Iran, a developing country, it was about 7.5 million sets [9]. According to research findings, a long-term use of computers can cause musculoskeletal problems in the upper-body parts, especially the neck, shoulders, arms, wrists and fingers $[9,12]$. Millions of computer users worldwide are susceptible to the risk of sore limbs. Previous body of research has showed a correlation between working on computer and the occurrence of such painful disorders $[13,14]$.

Postural control and maintenance is one's ability to keep the stability of different body parts and react against forces threatening a number of body limbs. To maintain the body's balance, the central nervous system can react to all this input with proper output. The musculoskeletal system should have a proper range of movement for certain activities. Muscle shrinkage or weakness caused by improper long-term posturing can lead to spasm and contraction [2]. In an extensive review study, the preva- 
lence rate of musculoskeletal diseases was estimated to be $9 \%-50 \%$ among keyboard users. In the control group, however, this rate was $4.5 \%-17 \%$ [15].

In 1997, the U.S. Bureau of Statistics estimated the number of injuries induced by such recurrent activities as typing on the keyboard or working on computer to be $92.576 ; 55 \%$ of these injuries affected the wrists [16]. Ehsani et al. (2013) reported a significant correlation between long-term working on computers and forward head posture. The chance of affliction with sore neck among those working on computers for more than 3 hours a day was estimated to be 5.52 times higher than those who spent less time on computers [17]. Long-term use of computers is very common among the university student population of Iran. Many students suffer from the pain induced by postural disorders. Investigating the underlying factors can help to prevent and treat these pains and enhance their health state.

Little research has been done so far concerning the postural damages faced by computer users in Iran. To the best of our knowledge, no such research has been carried out in Mashhad County. Therefore, the present study seeks to determine the prevalence rate of musculoskeletal damages and the relevant postural anomalies among computer users who studied Engineering at Ferdowsi University of Mashhad.

\section{Materials and Methods}

This descriptive research was carried out in 2015 on students of the School of Engineering Department who were enrolled in the academic year 2014-15 in Ferdowsi University of Mashhad. A total of 160 subjects volunteered to participate in this study and were selected by available sampling method. The selection criteria consisted of an average of three years of experience using computers and five hours of working with computer each day. People who were injured due to an accident or trauma were excluded. The average age of the population under study is $20.06 \pm 4.93$ years, the average height is $163.26 \pm 7.27 \mathrm{~cm}$, the average weight is $65.59 \pm 9.01 \mathrm{~kg}$, and the average body mass index (BMI) is $24.8 \pm 4.93$.

Data was collected by using a research questionnaire that consisted of two parts, and the results were analyzed. The first part consisted of information such as age, weight, height, and history of working with computers while the second part consisted of questions about injuries of the person who responded to the questionnaire. Cronbach's alpha test was used to evaluate internal compliance. Cronbach's alpha coefficient was 0.80 that reflects a relatively high reliability and an acceptable questionnaire. The reliability of the questionnaire was evaluated by using test-retest agreement, and it was found to be 0.73 to 0.88 , which is considered to be normal. For evaluation of the changes in postural alignment, the New York posture rating (NYPR) chart was used.

The NYPR was originally published in 1958 (The New York Physical Fitness Test), and its modified form was later published by Howley and Franks (1992) [18]. The NYPR applies a quantitative approach to assess proper and improper alignment of various body segments for an individual in the anatomical position. The NYPR published in 1958 includes a set of three figure drawings for each of 13 body alignment segments contributing to overall postural alignment. The 13 body alignment segments include posterior views of the head, shoulders, spine, hip, feet, and arches, and lateral (left side) views of the neck, chest, shoulders, upper back, trunk, abdomen, and lower back. Short verbal descriptions are provided to indicate the visual cues for use as criteria in deciding the score. In this original version, each body segment was scored 5 (correct posture), 3 (slight deviation), or 1 (pronounced deviation).

\section{Data analysis}

Excel software and SPSS Base 21.0 were used for data analysis. Data analyses were performed by analysis of descriptive statistics, calculation of the mean and standard deviation, and analysis of the charts.

\section{Results}

The distributed frequency and characteristics of participants in the study are presented in Table 1. The results of the damage questionnaire revealed that the prevalence of musculoskeletal disorders in computer users in the last three years (Table 2$)$ is in the head (81.25\%), eye $(87.50 \%)$, neck $(100 \%)$, shoulder $(100 \%)$, back $(81.25 \%)$, forearm $(75 \%)$, wrist $(100 \%)$, fingers $(100 \%)$, pelvis $(93.75 \%)$, and knees $(100 \%)$. Based on the results, the highest prevalence of musculoskeletal disorders among computer users (Table 3 ) has been reported in the area of the head, eyes, neck, shoulder, back, forearm, wrist, hand, hip, and knee, and the lowest degree of damage has been reported in parts of the legs, feet, toes and the palms. The causes and risk factors among computer users are continuous and excessive use of computers, inadequate rest, body fatigue at work, inadequate physical exercise and physical movement, and not following ergonomic conditions. 
The findings of this research indicated that the most prevalent postural anomalies among university students are as follows: $85 \%$ forward head posture, $90 \%$ drooping shoulders, $70 \%$ pectoral kyphosis, $65 \%$ posterior pelvic tilt, $40 \%$ bowed knees or X-shaped legs, and 30\% ankle rotation.

\section{Discussion}

The findings of the present research revealed that musculoskeletal damages are highly prevalent in the target population. The highest prevalence rate of musculoskeletal anomalies are as follows: $81.25 \%$ in the head, $87.5 \%$ in eyes, $100 \%$ in neck, $100 \%$ in shoulders, $81.25 \%$ in waist, $75 \%$ in forearms, $100 \%$ in wrists, $100 \%$ in fingers, $93.75 \%$ in pelvis, and $100 \%$ in knees. In Bastani and Lahmi's study, the highest rate of side effects was also observed in neck (53\%), back (48\%), and shoulders (12\%) [7].

A comparison of these two findings reveals that the highest prevalence rate of musculoskeletal damages among computer users is in the neck, waist, back, and shoulders. Since computer operation is a sedentary job and involves many recurrent movements, it mostly exposes the upper body parts such as the neck and back to musculoskeletal damages. A comparison of national (the present research as well as Bastani and Lahmi's) and international body of research reveals that the prevalence of musculoskeletal damages to the neck and back among computer users is much lower in Iran than it is in other countries.

In other parts of body, however, there is a little difference [7]. According to the results obtained, the prevalence rates of sore neck and sore shoulder were the same, i.e., equal to $100 \%$. This was higher than the findings reported by similar research in Sudan [12], China [13], New Zealand [9], and the Netherlands [15]. A body of research indicates that alternative keyboards can keep one's neck, shoulders, wrist and forearm in a neutral position and can, therefore, reduce the negative effects [15].

Other review studies carried out on this issue were also in line with the findings of the present research. In a cross-sectional study carried out by Choubineh et al., the highest prevalence rate of damages belonged to shoul- ders $(59.6 \%)$ and neck (58.2\%) among professional computer users working in the banks of Shiraz. These rates are lower than those found in the present study [19]. In another investigation conducted on 150 computer users in San Francisco (the U.S.), a significant correlation was found between the hours of using computer, limited choice at work, and musculoskeletal diseases [20]. This is similar to the finding of our research since university student computer users also referred to the constant use of computer as the main reason for musculoskeletal disorders. Among the other findings is the fact that longer hours of working on computers during the day and night further exhausts the eyes and other parts of the body. Working for long hours takes away the chance of resting and removing the tensions from the eyes. Looking at the monitor for long hours would reduce eye accommodation power and could lead to weakness, strain, and even headache [21]. Eyes play an essential role when working on a computer. To work optimally, they need enough rest depending on the working hours. Otherwise, one is initially faced with optic disorders such as strain, which would gradually lead to more serious complaints in later working years [22].

The results of the present research revealed that drooping shoulders, forward head posture, pectoral kyphosis, posterior pelvic tilt, bowed knees, X-shaped leg,s and ankle rotation are the prevalent postural anomalies among university student computer users. In the research reported by Bastani and Lahmi [7], the highest rate of side effects was observed in the neck (53\%), back (48\%), and shoulders (12\%). A comparison of these two reveals that the highest prevalence of musculoskeletal disorders among computer users is in the neck, back, waist, and shoulders. All these damages are induced by carelessness, no attention to correct rules and criteria, and no heed to the desirable standards required to be followed in both manufacturing computers and using them.

In a number of studies, a significant correlation has been reported between the abnormal positioning of the head and body while working (sitting in a rotated body posture or with a bent neck) and complaints of sore neck and shoulder [20]. Keeping one's neck bent to the front for a long time while working has been also stated to be

Table 1. Mean and standard deviation of age, height, and weight variables and body mass index of computer users.

\begin{tabular}{|c|c|c|c|c|c|}
\hline \multirow{2}{*}{ Group } & \multirow{2}{*}{ Number } & \multicolumn{4}{|c|}{ Mean \pm Standard Deviation } \\
\hline & & Age (Year) & Weight (Kg) & Height $(\mathrm{Cm})$ & Body Mass Index $\left(\mathrm{Kg} / \mathrm{m}^{2}\right)$ \\
\hline Computer users & 160 & $20.06 \pm 5.91$ & $59.65 \pm 8.4$ & $163.27 \pm 5.65$ & $24.80 \pm 2.99$ \\
\hline
\end{tabular}


Table 2. Frequency and prevalence of musculoskeletal injuries in computer users.

\begin{tabular}{|c|c|c|c|c|c|c|c|c|c|c|c|c|c|}
\hline \multirow{4}{*}{ Body Parts } & \multirow{4}{*}{ Organs } & \multicolumn{12}{|c|}{ Musculoskeletal Injuries } \\
\hline & & \multicolumn{6}{|c|}{ Fatigue } & \multicolumn{6}{|c|}{ Pain } \\
\hline & & \multicolumn{2}{|c|}{ Slight } & \multicolumn{2}{|c|}{ Medium } & \multicolumn{2}{|c|}{ Sever } & \multicolumn{2}{|c|}{ Slight } & \multicolumn{2}{|c|}{ Medium } & \multicolumn{2}{|c|}{ Sever } \\
\hline & & $\mathbf{F}$ & $\%$ & $\mathbf{F}$ & $\%$ & $\mathbf{F}$ & $\%$ & $\mathbf{F}$ & $\%$ & $\mathbf{F}$ & $\%$ & $\mathbf{F}$ & $\%$ \\
\hline \multirow{3}{*}{ Head and face } & Skull & 0 & 0 & 30 & 18.75 & 130 & 81.25 & 0 & 0 & 30 & 18.75 & 130 & 81.25 \\
\hline & & & & & & & & & & & & & \\
\hline & Eye & 0 & 0 & 20 & 12.50 & 140 & 87.50 & 0 & 0 & 20 & 12.50 & 140 & 87.50 \\
\hline \multirow{5}{*}{ Body and spine } & Neck & 0 & 0 & - & - & 160 & 100 & 0 & 0 & 0 & 0 & 160 & 100 \\
\hline & Back & 30 & 18.75 & 100 & 62.25 & 30 & 18.75 & 50 & 31.25 & 50 & 31.25 & 60 & 37.50 \\
\hline & & & & & & & & & & & & & \\
\hline & Waist & 10 & 6.25 & 20 & 12.50 & 130 & 81.25 & 20 & 12.50 & 10 & 6.25 & 130 & 81.25 \\
\hline & Rib & 60 & 37.50 & 80 & 50 & 20 & 12.50 & 60 & 37.50 & 80 & 50 & 20 & 12.50 \\
\hline \multirow{7}{*}{$\begin{array}{l}\text { Upper extremi- } \\
\quad \text { ties }\end{array}$} & Shoulder & 0 & 0 & 0 & 0 & 160 & 100 & 0 & 0 & 0 & 0 & 160 & 100 \\
\hline & Arm & 20 & 12.50 & 90 & 56.25 & 50 & 31.25 & 20 & 12.50 & 90 & 56.25 & 50 & 31.25 \\
\hline & Elbow & 20 & 12.50 & 90 & 56.25 & 50 & 31.25 & 20 & 56.25 & 90 & 56.25 & 50 & 31.25 \\
\hline & Forearm & 0 & 0 & 40 & 25 & 120 & 75 & 0 & 0 & 30 & 18.75 & 120 & 75 \\
\hline & Wrist & 0 & 0 & 0 & 0 & 160 & 100 & 0 & 0 & 0 & 0 & 160 & 100 \\
\hline & Palm & 20 & 12.50 & 90 & 56.25 & 50 & 80 & 40 & 25 & 90 & 56.25 & 30 & 18.75 \\
\hline & Fingers & 0 & 0 & 0 & 0 & 160 & 100 & 0 & 0 & 0 & 0 & 160 & 100 \\
\hline \multirow{7}{*}{$\begin{array}{l}\text { Upper extremi- } \\
\text { ties }\end{array}$} & Pelvis & 0 & 0 & 10 & 6.25 & 150 & 93.75 & 0 & 0 & 10 & 6.25 & 150 & 93.75 \\
\hline & Thigh & 70 & 43.75 & 60 & 37.50 & 30 & 18.75 & 70 & 43.75 & 60 & 37.50 & 30 & 18.75 \\
\hline & Knee & 0 & 0 & 0 & 0 & 160 & 100 & 0 & 0 & 0 & 0 & 160 & 100 \\
\hline & Leg & 110 & 68.75 & 40 & 25 & 10 & 6.25 & 110 & - & 40 & 25 & 10 & 6.25 \\
\hline & Ankle & 20 & 12.50 & 90 & 56.25 & 50 & 31.25 & 40 & 25 & 90 & 56.25 & 30 & 18.75 \\
\hline & Sole & 120 & 75 & 30 & 18.75 & 10 & 6.25 & 120 & 75 & 20 & 12.50 & 20 & 12.50 \\
\hline & Toes & 125 & 75 & 30 & 18.75 & 10 & 6.25 & 120 & 75 & 30 & 18.75 & 10 & 6.25 \\
\hline
\end{tabular}

significantly correlated with sore neck [20]. In an investigation carried out on 150 computer users in San Francisco, longer hours of working on computer and limited choice at work have been showed to be significantly correlated with musculoskeletal diseases [21].

This is in a similar line with the findings of this research study since the university student computer users also mentioned constant overwork as the main cause of their musculoskeletal diseases. In Germany, Sudan, Denmark, and Lebanon, female computer users also reported a higher rate of sore neck and shoulders, as compared to the male users. This gender-based difference in pain reports can be due to the fact that on the average, women tend to do more repetitive activities. However, men do not tend to work for long in a sedentary position. Moreover, mostly because of domestic chore and childcare, women are more susceptible to stress than men [22-24].

Many studies have investigated the damages and anomalies induced by PC and laptop computers. Among them are the works reported by Biswas and Lamba (2012). 
Table 3. Results of musculoskeletal disorders in computer users.

\begin{tabular}{cccccccccccc}
\hline Hyperlordosis & \multicolumn{2}{c}{ Lowered Shoulders } & \multicolumn{2}{c}{ Chest Kyphosis } & \multicolumn{2}{c}{ Posterior Pelvic Tilt } & \multicolumn{2}{c}{ GenoVarum and GenoValgum } & Ankle Deviation \\
\hline F & $\%$ & F & $\%$ & F & $\%$ & F & $\%$ & F & $\%$ & F & $\%$ \\
\hline 136 & 85 & 144 & 90 & 112 & 70 & 104 & 65 & 64 & 40 & 48 & 30 \\
\hline
\end{tabular}

Similar to our findings, they also reported that pectoral kyphosis and posterior pelvic tilt were more prevalent due to a stable and inappropriate posture in front of the computer. These anomalies are more severe in females than in males [25]. Gerr et al. (2004) also reported the occurrence of such anomalies as forward head posture, bowed knees or X-shaped legs, and rotated ankle as a function of daily activities such as studying and working on computer among financial clerks [26]. However, in previous studies, pectoral kyphosis was found to be induced by such activities as keeping one's hands forward for a long time [3, 27, 28].

As a result of these problems, one's body imposes the forward head posture in order to get coordinated and facilitate structural movements [29, 30]. In the case one is adequately susceptible to lordosis, an approximation of the above-mentioned problem worsens this disorder [30]. Considering this issue, performing ergonomic interventions in one's working environment seems to be essential. The limitations of this study include lack of control over the participants' lifestyle (the amount of sleep, rest and extra-curricular activities) and the small number of subjects considered in this study.

The prevalence of symptoms of musculoskeletal disorders in the target population was found to be high, especially in the head, eyes, forearm, wrist, fingers, neck, and knees. To treat these damages, people should use certain stretching and physical exercises designed for the limbs involved in working with computer. These exercises should be provided by physical educationalists.

Moreover, a well-designed workstation, proper instruction, and raising the awareness of ergonomic rules can help prevent chronic damage and fatigue among computer users. Furthermore, the forward head posture, drooping dominant shoulders of computer users, bowed knees or X-shaped legs were found to be the prevalent postural anomalies among university students. It had its origin in inactivity due to constant working on computers and not attending to ergonomic rules. Therefore, performing ergonomic interventions in the workplace seems to be essential. A well-designed workstation, instructing users and making them aware of ergonomic rules while working as well as creating variety at work and in their duties can be portions of this suggested program.

\section{Acknowledgments}

This research was carried out with personal funds. We express our gratitude to the Engineering students at the Faculty of Engineering of the Ferdowsi University of Mashhad.

\section{Conflict of Interest}

The author declared no Conflict of interests.

\section{References}

[1] Annesi JJ. Effects of computer feedback on adherence to exercise. Perceptual \& Motor Skills. 1998; 87(2):723-30. doi: 10.2466/pms.1998.87.2.723

[2] Mahmoodi F, Sharifian A. [The effect of corrective exercises on the degree of pain and shoulder asymmetry (Persian)]. Research in Sport Rehabilitation. 2014; 2(1):1-9.

[3] Buckle PW, Devereux JJ. The nature of work-related neck and upper limb musculoskeletal disorders. Applied Ergonomics. 2002; 33(3):207-17. doi: 10.1016/s0003-6870(02)00014-5

[4] Ellapen TJ, van Heerden HJ. Musculoskeletal posture profile analyses of University of Kwa-Zulu Natal students in South Africa. African Journal for Physical, Health Education, Recreation \& Dance. 2011; 17(4):880-87. doi: 10.4314/ajpherd. v17i1.65252

[5] Tinubu BM, Mbada CE, Oyeyemi AL, Fabunmi AA. Workrelated musculoskeletal disorders among nurses in Ibadan, South-west Nigeria: A cross-sectional survey. BMC Musculoskeletal Disorders. 2010; 11(1). doi: 10.1186/1471-2474-1112

[6] Spielholz P, Silverstein B, Morgan M, Checkoway H, Kaufman J. Comparison of self-report, video observation and direct measurement methods for upper extremity musculoskeletal disorder physical risk factors. Ergonomics. 2001; 44(6):588-613. doi: 10.1080/00140130118050

[7] Bastani S, Lahmi M. [Survey of musculoskeletal problems in the staff of computer site ergonomics and determination of risk factors (Persian)]. Paper presented at: The National 
Congress of Ergonomic and Manufacturing Industry; 2002 October 29; Tehran, Iran.

[8] Ranasinghe P, Perera YS, Lamabadusuriya DA, Kulatunga S, Jayawardana N, Rajapakse S, et al. Work-related complaints of arm, neck and shoulder among computer office workers in an Asian country: prevalence and validation of a riskfactor questionnaire. BMC Musculoskeletal Disorders. 2011; 12(1). doi: $10.1186 / 1471-2474-12-68$

[9] Harcombe H, McBride D, Derrett S, Gray A. Prevalence and impact of musculoskeletal disorders in New Zealand nurses, postal workers and office workers. Australian and New Zealand Journal of Public Health. 2009; 33(5):437-41. doi: 10.1111/j.1753-6405.2009.00425.x

[10] Eltayeb S, Staal JB, Hassan A, De Bie RA. Work related risk factors for neck, shoulder and arms complaints: a cohort study among Dutch computer office workers. Journal of Occupational Rehabilitation. 2009; 19(4):315-22. doi: 10.1007/ s10926-009-9196-x

[11] Andersen JH, Kaergaard A, Frost P, Thomsen JF, Bonde JP, Fallentin N, et al. Physical, psychosocial, and individual risk factors for neck/shoulder pain with pressure tenderness in the muscles among workers performing monotonous, repetitive work. Spine. 2002; 27(6):660-67. doi: 10.1097/00007632200203150-00017

[12] Eltayeb SM, Staal JB, Khamis AH, de Bie RA. Symptoms of neck, shoulder, forearms, and hands: A cohort study among computer office workers in Sudan. Clinical Journal of Pain. 2011; 27(3):275-81. doi: 10.1097/ajp.0b013e3181fe94ef

[13] Yue P, Liu F, Li L. Neck/shoulder pain and low back pain among school teachers in China, prevalence and risk factors. BMC Public Health. 2012; 12(1). doi: 10.1186/1471-2458-12789

[14] Linton SJ. A review of psychological risk factors in back and neck pain. Spine. 2000;25(9):1148-156. doi:10.1097/00007632200005010-00017

[15] Diepenmaat AC, Van der Wal MF, De Vet HC, Hirasing RA. Neck/shoulder, low back, and arm pain in relation to computer use, physical activity, stress, and depression among Dutch adolescents. Pediatrics. 2006; 117(2):412-16. doi: 10.1542 /peds.2004-2766

[16] Szeto GP, Straker LM, O'Sullivan PB. A comparison of symptomatic and asymptomatic office workers performing monotonous keyboard work-1: neck and shoulder muscle recruitment patterns. Manual Therapy. 2005; 10(4):270-80. doi: 10.1016/j.math.2005.01.004

[17] Ehsani F, Mosallanezhad Z, Ahmadizade Z, Taghipour M. Relationship between working with computer and forward head posture and neck pain among office workers. Physical Treatments. 2013; 3(2):29-33.

[18] Howley E, Franks B. Health fitness instructor's handbook $2^{\text {nd }}$ ed. Champaign: Human Kinetics Books Publishers, Inc.; 1992.

[19] Choobineh A, Mokhtarzadeh A, Salehi M, Tabatabaei SH. [Ergonomic evaluation of exposure to musculoskeletal disorders risk factors by QEC technique in a rubber factory (Persian)]. Jundishapur Scientific Medical Journal. 2008; 7(1):46-55.
[20] Faucett J, Rempel D. VDT-related musculoskeletal symptoms: Interactions between work posture and psychosocial work factors. American Journal of Industrial Medicine. 1994 26(5):597-612. doi: 10.1002/ajim.4700260503

[21] Hakala PT, Rimpelä AH, Saarni LA, Salminen JJ. Frequent computer-related activities increase the risk of neck-shoulder and low back pain in adolescents. European Journal of Public Health. 2006; 16(5):536-41. doi: 10.1093/eurpub/ ckl025

[22] Meislin RJ, Sperling JW, Stitik TP. Persistent shoulder pain: epidemiology, pathophysiology, and diagnosis. American journal of orthopedics (Belle Mead, NJ). 2005 Dec; 34(12 Suppl):5-9. PMID: 16450690

[23] Kendall FP, McCreary EK, Provance PG, Rodgers MM, Romani WA. Muscles: testing and function: with posture and pain. $5^{\text {th }}$ ed. Philadelphia: Lippincott Williams \& Wilkins; 2005.

[24] Penha PJ, João SM, Casarotto RA, Amino CJ, Penteado DC. Postural assessment of girls between 7 and 10 years of age. Clinics. 2005; 60(1):9-16. doi: 10.1590/s180759322005000100004

[25] Biswas A, Lamba D. To study and compare the effect of laptop computers with desktop computers on working posture and self-reported musculoskeletal symptoms. Indian Journal of Physiotherapy and Occupational Therapy. 2012; 6(3):106.

[26] Gerr F, Marcus M, Monteilh C. Epidemiology of musculoskeletal disorders among computer users: lesson learned from the role of posture and keyboard use. Journal of Electromyography \& Kinesiology. 2004; 14(1):25-31. doi: 10.1016/j.jelekin.2003.09.014

[27] Mazloum V, Sahebozamani M. [The effects of various exercise-based interventions on non-specific chronic low back pain: A systemic review on Persian studies (Persian)]. Journal of Research in Rehabilitation Sciences. 2015; 11(1):89-98.

[28] Ghotbi N, Hassanpour A. [Effect of somatosensory impairments on balance control (Persian)]. Audiology. 2012; 21(3):1-8.

[29] Kim DQ, Cho SH, Han TR, Kwon HJ, Ha M, Paik NJ. The effect of VDT work on work-related musculoskeletal disorder. Korean Journal of Occupational and Environmental Medicine. 1998; 10(4):524-33.

[30] Jindrich DL, Balakrishnan AD, Dennerlein JT. Effects of keyswitch design and finger posture on finger joint kinematics and dynamics during tapping on computer keyswitches. Clinical Biomechanics. 2004; 19(6):600-08. doi: 10.1016/j.clinbiomech.2004.03.003 